\title{
Childhood Hearing Is Associated With Growth Rates in Infancy and Adolescence
}

\author{
DAVID WELCH AND PATRICK J.D. DAWES \\ Department of Preventive and Social Medicine [D.W.], Department of ORL-HNS [P.J.D.D.], Dunedin School of Medicine, \\ University of Otago, Dunedin 9054, New Zealand
}

\begin{abstract}
It is known that shorter stature is associated with sensorineural hearing loss; and that cochlear development is associated with activity of IGF 1 , as are many important aspects of neurodevelopment. We hypothesized that this relation might be extrapolated to a normally hearing group, and that the strongest relation between hearing level and growth rate would be in late puberty, when serum IGF-1 levels are highest. We examined the statistical relation between childhood hearing threshold and rate of growth in height at different times during the life course up to age 32. We found mixed support for the hypothesis. The strongest relations were observed in late puberty, at the ages which previous research shows are associated with the highest serum concentrations of IGF-1 in males and females, but also in infancy and early childhood. The association between hearing and height is present in a normally hearing, general population sample, and is associated with growth in late adolescence. Our findings support the idea that childhood hearing threshold may be predictive of IGF-1 mediated developmental characteristics. (Pediatr Res 62: 495-498, 2007)
\end{abstract}

$\mathrm{P}$ revious research has demonstrated that sensorineural hearing loss in adulthood is associated with short stature, and it has been postulated that this is due to low levels of IGF 1 $(1,2)$. IGF-1 is involved in the process of shaping the developing cochlea, having a role in preventing apoptosis (3), its lack is known to produce sensorineural hearing loss in humans (4-6), and it may also play a role in the protection of the cochlear outer hair cells $(7,8)$. IGF-1 is also known to influence physical stature, particularly during the adolescent growth spurt $(9,10)$. In Turner's syndrome, a condition associated with reduced sensitivity to growth hormone, it has been shown that hearing is correlated with serum IGF-1 levels (11). Furthermore, mutations of the IGF-1 gene can lead to growth, neurologic, and hearing deficits when homozygous (4-6), and people who are heterozygotic for these mutations may tend in the same direction (5), though heterozygotic effects in hearing were not detected in a mouse model (12).

Variation in normal hearing ability stems from both external sources such as noise, infections, and ototoxic agents; and internal sources. We have demonstrated that variation in hearing level within the normal range (i.e., better than $15 \mathrm{~dB}$

Received April 18, 2007; accepted May 20, 2007.

Correspondence: David Welch, Ph.D., DMHDRV Department of Preventive and Social Medicine, Dunedin Multidisciplinary Health and Development Research Unit, Dunedin School of Medicine, University of Otago, PO Box 913, Dunedin 9054, New Zealand; e-mail: david.welch@dmhdru.otago.ac.nz

The Dunedin Multidisciplinary Health and Development Research Unit is funded by the Health Research Council of New Zealand.
HL) is associated with a range of behavioral and social outcomes in children (13). If a low level of IGF-1 impairs cochlear development to produce hearing loss, less extreme variation in IGF-1 levels may be one factor in the determination of normal hearing ability. Given that the IGF system is also associated with adolescent growth in physical stature, and that height and hearing ability covary, the aim of this research was to determine whether variation in normal hearing level measured in a general-population sample of children was associated with growth.

\section{METHOD}

Participants were members of the Dunedin Multidisciplinary Health and Development Study, a longitudinal investigation of health and behavior in a birth cohort (14). The study members were born in Dunedin, New Zealand between April 1972 and March 1973. Of these individuals, 1037 children (91\% of eligible births; $52 \%$ male) participated in the first follow-up assessment at age 3, which constituted the base sample for the remainder of the study. Cohort families represented the full range of socioeconomic status in the general population of New Zealand's South Island and were mainly white of European descent. Follow-ups were done at ages 5, 7, 9, 11, 13, 15, 18, 21, 26, and most recently at age $32 \mathrm{y}$ when we assessed $972(96 \%)$ of the 1015 study members still alive. The Otago Ethics Committee granted ethics approval for each phase of this longitudinal study. Study members and their parents gave informed consent before participating.

Hearing measure. The pure-tone average (PTA) was developed as an overall measure of hearing in childhood. It was based on standard pure-tone audiometry which was conducted at four ages $(5,7,9$, and 11), and this process is described more fully elsewhere (13). Briefly, the measure was developed according to previous research demonstrating that hearing disability in adults best correlates with a pure-tone average based on the $0.5,1$, and $2 \mathrm{kHz}$ thresholds, and an average across ears calculated using a weighting ratio of $4: 1$ with respect to the better hearing ear (15). Since we were interested in sensorineural hearing level, not the impacts of middle-ear disease, we excluded anyone from whom less than two thresholds were measured under normal middle ear conditions (i.e., Type A or C1 tympanogram) during childhood $(n=303)$. Since we were interested in those with normal (i.e., better than $15 \mathrm{~dB}$ HL) hearing ability, the 23 people with overall PTA worse than $15 \mathrm{~dB}$ HL were also excluded from analyses. The final measure of PTA used was the mean score for the 711 people who had undergone at least two audiograms with normal middle ear conditions during childhood, and for whom the mean was no poorer than $15 \mathrm{~dB}$ HL.

Socioeconomic status. To control for confounding effects associated with socioeconomic status throughout childhood (e.g., diet), it was included in all statistical models. The variable used was an average from birth to age 15, based upon parental occupation at each age rated according to a six point scale where low values represent unskilled labor, and high represent the professions (16).

Stature. Height was measured in millimeters at every assessment age from birth to $32 \mathrm{y}$. Growth between each measurement age was calculated (Fig. 1).

Abbreviations: PTA, pure-tone average 


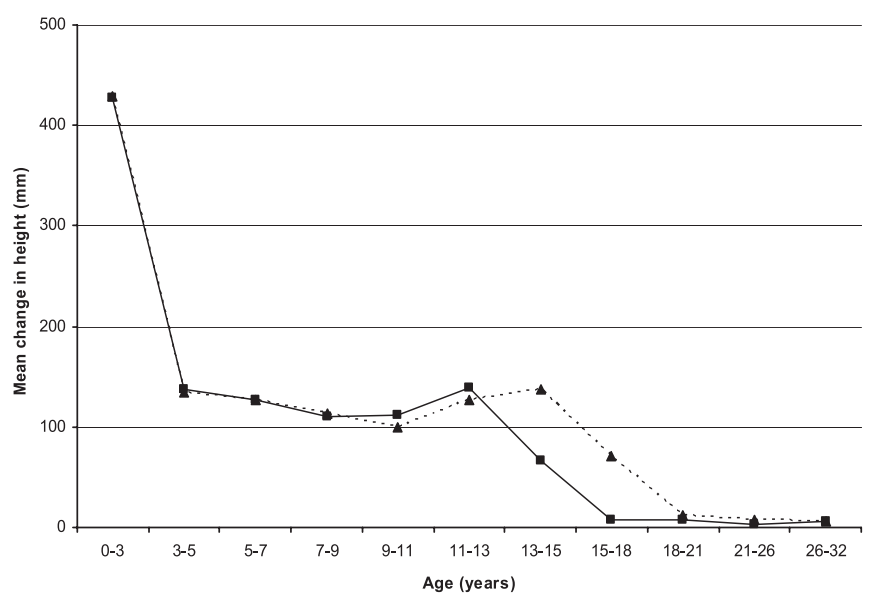

Figure 1. Mean growth (mm) between each assessment age. Females: $\square$ and solid line; males: $\boldsymbol{\Delta}$ and broken line.

Data analysis. Two sets of multiple linear regression models were conducted. In the first set, childhood PTA was used to predict height at each age. In the second set, the relation between childhood PTA and growth from one assessment to the next was assessed by controlling for height at the previous age. All analyses were controlled for childhood socioeconomic status, and were conducted separately by sex because of different growth patterns in the two sexes.

\section{RESULTS}

Peak growth was between birth and age three for both sexes, and the secondary peak was between age 11 and 13 for females, and between age 13 and 15 for males (Fig. 1).

The first set of analyses showed that childhood PTA predicted height in both males and females. In both sexes, there were two peaks of predictive power, once in early childhood, and once at age 18 (Fig. 2). After age 18, the predictive ability of childhood PTA dropped slightly then remained approximately constant to age 32 .

The second set of analyses demonstrated that childhood hearing ability was associated with growth rates during infancy and late puberty (Fig. 3). The peak regression coeffi-

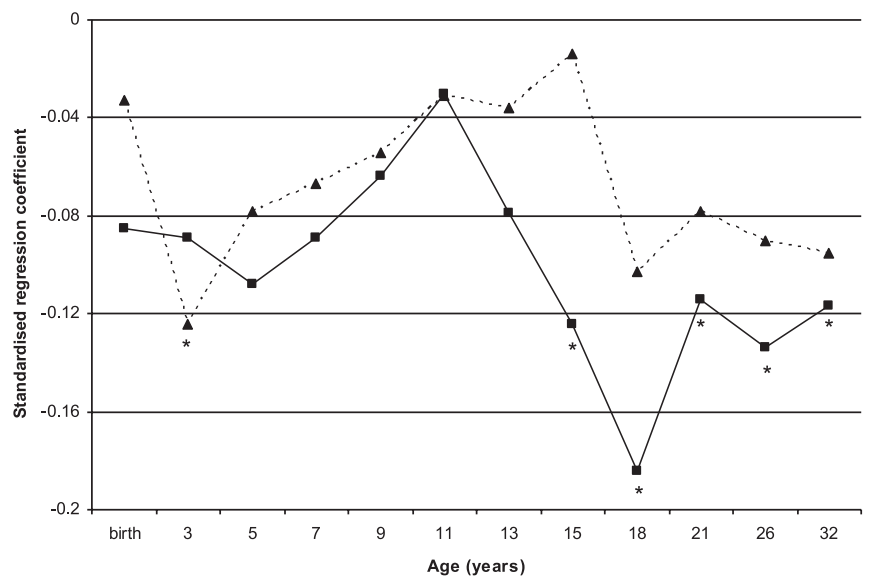

Figure 2. Standardized regression coefficients relating childhood hearing (PTA) to height throughout the life course to age 32. Coefficients are all negative implying that better childhood hearing (i.e., lower threshold) was associated with being taller. Asterisks denote coefficients significantly different from zero at $p=0.05$. Females: $\boldsymbol{\square}$ and solid line; males: $\boldsymbol{\Lambda}$ and broken line.

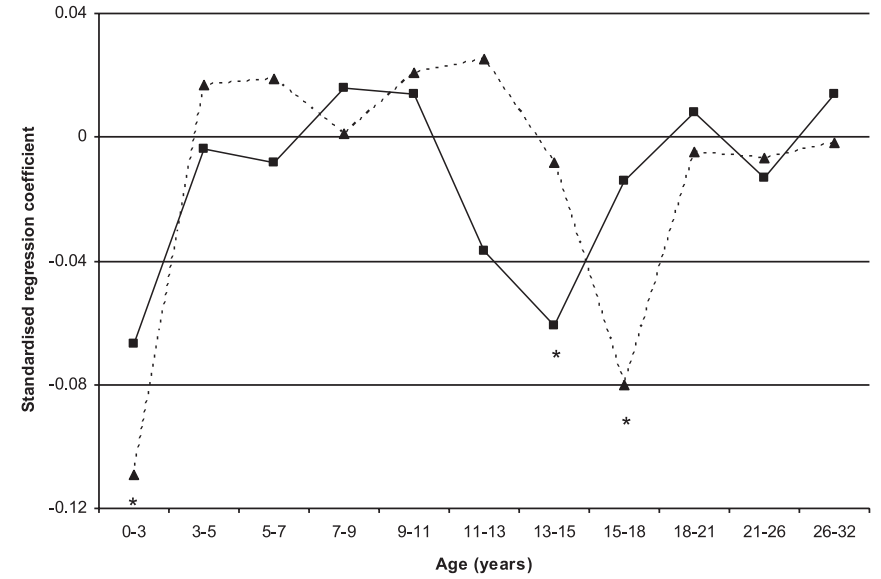

Figure 3. Standardized regression coefficients relating childhood hearing (PTA) to growth throughout the life course to age 32. Growth was modeled by inclusion of height at the beginning of each age range as a covariate in multiple linear regression models of height at the end of each age range. Negative coefficients imply that better childhood hearing (i.e., lower threshold) was associated with more growth. Asterisks denote coefficients significantly different from zero at $p=0.05$. Females: $\boldsymbol{\square}$ and solid line; males: $\boldsymbol{\Delta}$ and broken line.

cients were in the birth to age 3 period for both sexes, from age 13 to 15 for females, and from age 15 to 18 for boys.

\section{DISCUSSION}

This research has shown a number of interesting findings. The first of these is that normal hearing is associated with height in a general population sample. Linear regression modeling showed that, those with better childhood hearing levels tended to be taller (Fig. 2). While this effect was small at most ages, the association was stronger at ages $3-5 \mathrm{y}$, and at age 18; these being the periods of maximal growth.

Growth from birth to age three and during late adolescence was predicted by childhood hearing level in both males and females (Fig. 3). There were two sets of peaks in the graph of predictive power for childhood hearing level and growth; from birth to age three, and during adolescence. For females, the adolescent peak predictive power for childhood hearing on growth (age 13 to 15; Fig. 3) occurred after peak growth (age 11 to 13; Fig. 1); and for males the same sort of discrepancy was observed, peak growth was between ages 13 and 15, while peak predictive power for childhood hearing on growth was between ages 15 and 18 .

The findings of peak predictive power for childhood hearing on growth rate in adolescence are consistent with previous research which has shown that peak concentrations of serum IGF-1 occur at age 14.5 for females and 15.5 for males, i.e., later than the peaks in growth rate (10). Presumably the earlier part of the growth spurt reflects the action of sex hormones, which have no impact on cochlear development; and the later growth reflects the function of the IGF system, given that IGF-1 concentration is known to increase toward the end of puberty (17). This may also explain why the maximum regression coefficient relating childhood hearing to height was not until age 18 (Fig. 2); if IGF-1 mediated growth is predicted by childhood hearing level, it had to be 
completed before the predictive effect of hearing on height would be detectable.

While the association between growth and hearing levels was strong in late puberty, when serum IGF-1 levels are high, we also observed peaks in the relationship between PTA and growth rate during the period from birth to age 3 , a period when IGF-1 levels are known to be low $(10,18)$. Previous work has shown links between IGF-1 levels in Turner's syndrome and hearing (11), and reduced growth in Turner's syndrome in infancy (19), and other studies have shown that genetic mutations associated with abnormal IGF-1 are also predictive of poor hearing and infant growth (4-6). Thus, it may be supposed that relatively small influences on the IGF system during infancy could influence both development of the hearing system and growth rate during this period.

A possible explanation for the effects observed here is a variable degree of heterozygosity in genes associated with low IGF-1. The lack of a statistical difference between heterozygous and normal mice (12) may not discount this. Possibly, individuals with genetic predisposition to produce less IGF-1 may end up with less redundancy in sensory cells, causing no detectable differences in hearing in one month old cochleae as assessed in mice, but with detectable effects in the ears of children between 5 and $11 \mathrm{y}$ of age as we studied. Another possibility is suggested by comparison of the brainstem auditory evoked potentials for the lower level $(30-60 \mathrm{~dB})$ stimuli used by Cediel et al. (their Fig. 1), which are clearer in the normal than in the heterozygous mice. It may be that heterozygous individuals have poorer than normal development in the structures involved in the cochlear active process, so that effects are noticeable only at very low levels around the audiometric threshold; such levels as were used in the present research.

We have shown previously that variation in childhood hearing within the normal range is associated with childhood IQ, language abilities, identification of speech in noise, and with behavioral problems in girls (13). We hypothesized three potential causes of variability in PTA as mechanisms underlying these relationships: noise or disease insults, psychological factors, and neurodevelopmental factors. The current findings linking hearing level to the IGF system support the idea that neurodevelopmental factors may play a part in the link between variability in normal hearing and the observed outcomes. This effect would be both parallel, in that development of the hearing system would be effected as well as other neuronal systems, and also sequential, in that slightly poorer hearing may contribute to the neurodevelopmental impacts. These associations between hearing, cognition, behavior, and growth are also consistent with previous research which has shown relationships between cognitive functioning, behavior, and height through childhood and adolescence both in the same birth cohort as the present study (20), and in other children (21). The present findings, when combined with these earlier studies imply that the IGF system may be a common feature underlying all of the observed associations. Future longitudinal research may potentially test this hypothesis directly by measuring serum IGF-1 levels at the relevant ages and determining whether variation in it is associated with the other variables suggested here. Similarly, investigation of IGF-1 gene mutations in comparison with the level of normal hearing ability in humans would be of interest.

Previous research has demonstrated associations between hearing loss in adulthood and small stature (1), and between hearing loss in childhood and low birth weight (22). We have shown associations between variability in normal hearing level in childhood and rate of growth in infancy and late puberty, with the strongest associations being at the ages when serum IGF-1 concentration is highest for each sex. An explanation for our findings is that variation in the IGF system mediates both hearing level within the normal range in childhood and growth in late puberty and early infancy. The findings are interesting because they occur in a generalpopulation sample, and among those whose hearing level was good (i.e., no worse than $15 \mathrm{~dB}$ HL). Our findings build upon laboratory research, which shows a role for IGF-1 in cochlear development and maintenance, and provide longitudinal support for this. This research also bears upon our own earlier findings of poorer behavior and neurocognitive ability in those with poorer normal childhood hearing level (13) in that the differences we found previously may be, at least partly, explained by activity of the IGF system.

\section{REFERENCES}

1. Barrenas M-L, Bratthall A, Dahlgren J 2005 The association between short stature and sensorineural hearing loss. Hear Res 205:123-130

2. Barrenas M-L, Jonsson B, Tuvemo T, Hellstrom P-A, Lundgren M 2005 High risk of sensorineural hearing loss in men born small for gestational age with and without obesity or height catch-up growth: a prospective longitudinal register study on birth size in 245,000 Swedish conscripts. J Clin Endocrinol Metab 90:4452-4456

3. Varela-Nieto I, Morales-Garcia JA, Vigil P, Diaz-Casares A, Gorospe I, Sanchez-Galiano S, Canon S, Camarero G, Contreras J, Cediel R, Leon Y 2004 Trophic effects of insulin-like growth factor-I (IGF-I) in the inner ear. Hear Res 196:19-25

4. Bonapace G, Concolino D, Formicola S, Strisciuglio P 2003 A novel mutation in a patient with insulin-like growth factor 1 (IGF1) deficiency. J Med Genet 40:913-917

5. Walenkamp MJ, Karperien M, Pereira AM, Hilhorst-Hofstee Y, van Doorn J, Chen JW, Mohan S, Denley A, Forbes B, van Duyvenvoorde HA, van Thiel SW, Sluimers CA, Bax JJ, de Laat JA, Breuning MB, Romijn JA, Wit JM 2005 Homozygous and heterozygous expression of a novel insulin-like growth factor-I mutation. J Clin Endocrinol Metab 90:2855-2864

6. Woods KA, Camacho-Hubner C, Savage MO, Clark AJ 1996 Intrauterine growth retardation and postnatal growth failure associated with deletion of the insulin-like growth factor I gene. N Engl J Med 335:1363-1367

7. Iwai K, Nakagawa T, Endo T, Matsuoka Y, Kita T, Kim T-S, Tabata Y, Ito J 2006 Cochlear protection by local insulin-like growth factor-1 application using biodegradable hydrogel. Laryngoscope 116:529-533

8. Malgrange B, Rigo J-M, Coucke P, Thiry M, Hans G, Nguyen L, van de Water TR, Moonen G, Lefebvre PP 2002 Identification of factors that maintain mammalian outer hair cells in adult organ of Corti explants. Hear Res 170:48-58

9. Chellakooty M, Juul A, Boisen KA, Damgaard IN, Kai CM, Schmidt IM, Petersen JH, Skakkebaek NE, Main KM 2006 A prospective study of serum insulin-like growth factor I (IGF-I) and IGF-binding protein-3 in 942 healthy infants: associations with birth weight, gender, growth velocity, and breastfeeding. J Clin Endocrinol Metab 91:820-826

10. Juul A, Bang P, Hertel NT, Main K, Dalgaard P, Jorgensen K, Muller J, Hall K, Skakkebaek NE 1994 Serum insulin-like growth factor-I in 1030 healthy children, adolescents, and adults: relation to age, sex, stage of puberty, testicular size, and body mass index. J Clin Endocrinol Metab 78:744-752

11. Barrenas M, Landin-Wilhelmsen K, Hanson C 2000 Ear and hearing in relation to genotype and growth in Turner syndrome. Hear Res 144:21-28

12. Cediel R, Riquelme R, Contreras J, Diaz A, Varela-Nieto I 2006 Sensorineural hearing loss in insulin-like growth factor I-null mice: a new model of human deafness. Eur J Neurosci 23:587-590

13. Welch D, Dawes PJD 2007 Variation in the normal hearing threshold predicts childhood IQ, linguistic, and behavioral outcomes. Pediatr Res 61:737-744

14. Silva PA, Stanton WR 1996 From Child to Adult: The Dunedin Multidisciplinary Health and Development Study. Oxford University Press, Auckland 
15. Lutman ME, Brown EJ, Coles RR 1987 Self-reported disability and handicap in the population in relation to pure-tone threshold, age, sex and type of hearing loss. $\mathrm{Br} \mathrm{J}$ Audiol 21:45-58

16. Elley WB, Irving JC 1972 A socio-economic index for New Zealand based on levels of education and income from the 1966 census. N Z J Educational Studies 7:153-167

17. Blogowska A, Rzepka-Gorska I, Krzyzanowska-Swiniarska B 2003 Growth hormone, IGF-1, insulin, SHBG, and estradiol levels in girls before menarche. Arch Gynecol Obstet 268:293-296

18. Juul A, Holm K, Kastrup KW, Pedersen SA, Michaelsen KF, Scheike T, Rasmussen S, Muller J, Skakkebaek NE 1997 Free insulin-like growth factor I serum levels in 1430 healthy children and adults, and its diagnostic value in patients suspected of growth hormone deficiency. J Clin Endocrinol Metab 82:2497-2502
19. Davenport ML, Punyasavatsut N, Stewart PW, Gunther DF, Savendahl L, Sybert VP 2002 Growth failure in early life: an important manifestation of Turner syndrome. Horm Res 57:157-164

20. Pryor J, Silva PA, Brooke M 1995 Growth, development and behaviour in adolescents born small-for-gestational-age. J Paediatr Child Health 31:403407

21. Dowdney L, Skuse D, Morris K, Pickles A 1998 Short normal children and environmental disadvantage: A longitudinal study of growth and cognitive development from 4 to 11 years. J Child Psychol Psychiatry 39:1017-1029

22. Elgen I, Johansson KA, Markestad T, Sommerfelt K 2005 A non-handicapped cohort of low-birthweight children: growth and general health status at 11 years of age. Acta Paediatr 94:1203-1207 